\title{
National Survey of Attitudes and Practices of Endotracheal Tube Management in Infants and Small Children in Japan
}

\author{
Masayuki Shibasaki1, Yasuyuki Suzuki2*, \\ Tetsuro Kagawa3 ${ }^{3}$, Yasuhiro Kogure ${ }^{2}$, \\ Keiichiro Mizuno ${ }^{4}$, Nobuaki Shime ${ }^{5}$
}

${ }^{1}$ Department of Anesthesiology, Kyoto Prefectural University of Medicine, Kyoto, Japan

${ }^{2}$ Department of Critical Care and Anesthesia, National Center for Child Health and Development, Tokyo, Japan

${ }^{3}$ Department of Anesthesia, Hyogo Prefectural Kobe Children's Hospital, Kobe, Japan

${ }^{4}$ Department of Anesthesia, Fukuoka Children's Hospital, Fukuoka, Japan

${ }^{5}$ Department of Emergency and Critical Care Medicine, Hiroshima University, Hiroshima, Japan

Email: *suzuki-y@ncchd.go.jp

How to cite this paper: Shibasaki, M., Suzuki, Y., Kagawa, T., Kogure, Y., Mizuno, K. and Shime, N. (2019) National Survey of Attitudes and Practices of Endotracheal Tube Management in Infants and Small Children in Japan. Open Journal of Anesthesiology, 9, 9-22.

https://doi.org/10.4236/ojanes.2019.92002

Received: December 24, 2018

Accepted: January 28, 2019

Published: January 31, 2019

Copyright $\odot 2019$ by author(s) and Scientific Research Publishing Inc. This work is licensed under the Creative Commons Attribution International License (CC BY 4.0). http://creativecommons.org/licenses/by/4.0/

\section{Open Access}

\begin{abstract}
Background: Surveys of pediatric endotracheal tube (ETT) management previously reported that specialists in pediatric anesthesia and intensive care medicine preferred to use uncuffed ETTs for children younger than 8 to 10 years of age. The aim of this study was to reveal the most recent attitudes and clinical practices of pediatric ETT management in Japan. Methods: The attitudes and clinical practices of pediatric ETT management were investigated using the data sheets of each institution and each patient. The data sheets contained information on patient characteristics and type of hospital, surgical procedures, devices used for intubation, and ETT information including types, size, depth, intracuff pressure (ICP), interval of ICP measurement, laryngeal packing, ETT exchange, airway complications, and reintubations. Results: The response rate of this survey was $66.7 \%$. More than half of children older than 2 years of age were intubated with cuffed ETTs; $83.5 \%$ of cuffed ETTs were used with the cuffs inflated, and ICP was measured in 80.7\% of cuffed ETTs. More than half of ICP measurements were only taken at the time of intubation. Post-extubation stridor was rarely observed in cuffed $(0.4 \%)$ or uncuffed ETTs $(1.2 \%)$. The pediatric ETT management questionnaire revealed age-based size selection, differences in pressure of air leakage between cuffed $\left(15-20 \mathrm{cmH}_{2} \mathrm{O}\right)$ and uncuffed ETTs $\left(20-30 \mathrm{cmH}_{2} \mathrm{O}\right)$ of different sizes, the depth-marking method of insertion length. Continuous measurement of ICP was not common. Conclusion: This study revealed
\end{abstract}


widespread use of cuffed ETTs in children older than 2 years of age, rarely occurrence of post-extubation stridor, inflation of cuffs, and practice of ICP measurement.

\section{Keywords}

Cuffed Endotracheal Tube, Size Selection, Depth Determination, Intracuff Pressure, Infants, Small Children

\section{Introduction}

Uncuffed endotracheal tubes (ETTs) have traditionally been used for infants and children younger than 8 to 10 years of age [1] [2]; the same practices were also reported in France [3] in 2001 and in the UK [4] in 2008. This was the result of concern over airway complications due to cuffs, and of incremental airway resistance and increased breathing effort due to the smaller size of cuffed ETTs [3] [5] [6] [7]. Previous studies reported that cuffed ETTs had better clinical outcomes than uncuffed ETTs, including exchange of ill-fitting tubes, exposure of anesthetic gases, consumption of fresh gas, incidence of stridor, additional racemic epinephrine treatment after extubation, efficacy of ventilation, and reliability of capnography [8]-[13]. However, sophisticated cuff design and the good clinical outcomes of cuffed ETTs might encourage the use of cuffed ETTs for infants and children younger than 10 years of age. A novel pediatric ETT with a high-volume low-pressure cuff was developed in 2004 [14], and it was introduced in Japan in 2015. This ETT has a $10 \mu \mathrm{m}$ of ultra-thin polyurethane cuff which is resistant to high intracuff pressure up to $800 \mathrm{~cm} \mathrm{H}_{2} \mathrm{O}$. Its cuff is located more distal than other cuffed ETTs, since this ETT has no Murphy eyes. The aims of this study were to reveal the most recent attitudes and practices of pediatric ETT management in Japan.

\section{Patients and Methods}

The protocol for this study was approved by the Japanese Society of Pediatric Anesthesiology (JSPA). After obtaining approval from the institutional ethical review board of each participating hospital, surveys were administered regarding the practices and attitudes of pediatric ETT management in 63 hospitals where councilors of JSPA work. Councilors of JSPA are the specialists of pediatric anesthesia defined by JSPA. This study had two parts: to investigate the practice of pediatric ETT management, and to survey the attitudes of pediatric ETT management. This study was performed over 2 weeks, between July 4, 2016 and July 17, 2016. The practice of pediatric ETT management was investigated for all general anesthesia between July 4, 2016 and July 17, 2016. The sample size of investigation of the practice of pediatric ETT management was not calculated, because this study was performed based on period. 


\subsection{Investigation of Pediatric ETT Management Practices}

The investigation of pediatric ETT practices was performed using the data sheet of each patient. The data sheet was designed and prepared for this study. The data sheet included information on patient characteristics and type of hospital, supervisors, surgical procedures, and devices for intubation, and ETT information including products, cuffed or uncuffed style, type, size, depth, intracuff pressure (ICP), intracuff volume (ICV), intervals of ICP measurement, laryngeal packing, ETT exchange, airway complications, and reintubations. Included patients were children weighing more than $2.5 \mathrm{~kg}$ and less than 9 years of age who were intubated for general anesthesia by anesthesiologists. Exclusion criteria were already intubated patients, patients with already known airway morbidity (such as subglottic stenosis, tracheal stenosis, and tracheomalacia), and patients who had been intubated for reasons other than anesthesia.

\subsection{Survey of the Institutional Attitudes of Pediatric ETT Management}

The questionnaire regarding the institutional attitude of pediatric ETT management used in this study was made by the working group of this study in JSPA based on the previous reports [3] [4]. The questionnaire regarding the institutional attitude of pediatric ETT management was as follows:

1) Do you have institutional criteria for selection of the type (cuffed, uncuffed, or reinforced) of ETT?
a) Age
b) Height
c) Surgical procedure
d) Patient position
e) Other
f) No criteria

2) Do you have institutional criteria for the selection of a cuffed ETT?
a) Not used for neonates under $3 \mathrm{~kg}$
b) No weight-based criteria
c) Older than neonate
d) More than ( ) months old
e) More than ( ) years old
f) Other (ex.: surgical procedure, patient position, etc.)

3) Do you have institutional criteria for the selection of ETT size?
a) Age
b) Weight
c) Height
d) Fifth finger
e) Recommendation of manufacturer
f) Other 
g) No criteria

4) Do you check air leakage to determine optimal ETT size?
a) Uncuffed ( $\quad \mathrm{cmH}_{2} \mathrm{O}$
b) Cuffed ( $\quad \mathrm{cmH}_{2} \mathrm{O}{ }^{\star}$ Deflated cuff (Yes, No)
c) Not checked

5) Do you have institutional criteria for the determination of ETT depth?
a) Depth marking
b) Calculation based on height
c) Calculation based on age
d) Calculation based on weight
e) Calculation based on internal ETT diameter
f) Bilateral auscultation on withdrawal of the ETT from bronchial intubation
g) Other
h) No criteria

6) Do you have institutional criteria for ICP management?
a) No inflated cuffs
b) $(\quad) \mathrm{cmH}_{2} \mathrm{O}$
c) No criteria
d) Not measured

7) Do you have institutional criteria for ICP measurement?
a) Continuous measurement
b) At ( )-minute intervals
c) Only once

\section{Results}

The response rate of this survey was $66.7 \%$ (42/63 hospitals). We received the results of 915 cases (366 females, 548 males, and 1 unknown) from 42 hospitals (10 general hospitals, 22 university hospitals, and 10 children's hospitals). The socio-demographic characteristics of the patients were shown in Table 1.

The most-used device for intubation was the laryngoscope (93.0\%); video-assisted laryngoscopes (6.5\%) and bronchofiberscopes $(0.3 \%)$ were rarely used. Both cuffed and uncuffed ETTs used included more than 5 different brands (PORTEX (36.3\%), Mallinckrodt (31.8\%), Microcuff (24.0\%), Parker

Table 1. Socio-demographic characteristics of the patients.

\begin{tabular}{|c|c|c|c|c|c|c|c|c|c|c|c|}
\hline & Neonate & $<1 \mathrm{yr}$ & $<2 \mathrm{yr}$ & $<3 \mathrm{yr}$ & $<4 \mathrm{yr}$ & $<5 \mathrm{yr}$ & $<6 \mathrm{yr}$ & $<7 \mathrm{yr}$ & $<8 \mathrm{yr}$ & $<9 \mathrm{yr}$ & Total \\
\hline $\begin{array}{c}\text { Number of } \\
\text { patients }\end{array}$ & 21 & 180 & 179 & 113 & 97 & 82 & 98 & 64 & 41 & 40 & 915 \\
\hline Gender $(\mathrm{M} / \mathrm{F})$ & $15 / 6$ & $113 / 67$ & $107 / 71^{\star}$ & $70 / 43$ & $60 / 37$ & $44 / 38$ & $54 / 44$ & $33 / 31$ & $26 / 15$ & $26 / 14$ & $548 / 366^{*}$ \\
\hline Age (months) & $11.5 \pm 9.4^{\star \star}$ & $5.8 \pm 3.3$ & $16.8 \pm 3.6$ & $28.3 \pm 3.6$ & $41.5 \pm 3.5$ & $52.9 \pm 3.1$ & $65.3 \pm 3.5$ & $77.1 \pm 3.4$ & $88.7 \pm 3.3$ & $101.2 \pm 3.6$ & --- \\
\hline Height $(\mathrm{cm})$ & $49.9 \pm 0.6$ & $63.1 \pm 7.5$ & $75.6 \pm 5.1$ & $84.7 \pm 6.8$ & $93.0 \pm 5.9$ & $99.5 \pm 6.2$ & $108.4 \pm 5.7$ & $112.3 \pm 8.1$ & $116.7 \pm 8.8$ & $123.0 \pm 7.1$ & --- \\
\hline Weight (kg) & $2.7 \pm 0.0$ & $6.4 \pm 1.8$ & $9.8 \pm 1.8$ & $11.5 \pm 2.3$ & $13.8 \pm 1.2$ & $15.5 \pm 2.4$ & $17.4 \pm 2.7$ & $20.1 \pm 3.0$ & $21.3 \pm 1.8$ & $22.3 \pm 2.5$ & --- \\
\hline
\end{tabular}

* Unknown gender in one case; ${ }^{* *}$ Age is expressed as days. 
(4.8\%), Sheridan (0.5\%), and Other (2.5\%)). The types of ETT used were the normal ETT (83.1\%), preformed ETT (14.4\%), and reinforced ETT (2.5\%).

\subsection{Use of Cuffed ETTs}

More than half of patients in university hospitals (55.7\%) and children's hospitals (56.9\%) were intubated with cuffed ETTs. In general hospitals, cuffed ETTs were used in less than half of cases (45.0\%).

The Japanese Society of Anesthesiologists (JSA) has 3 types of certifications for anesthesiologists. The lowest level of certification is a JSA Qualified Anesthesiologist, the middle level is a JSA Board Certified Anesthesiologist, and the highest level is a Fellow of JSA. More than half of cases were intubated with cuffed ETTs among all levels of anesthesiologists (JSA Qualified Anesthesiologist (61.0\%), JSA Board Certified Anesthesiologist (52.8\%), Fellow of JSA (55.4\%)). Analysis of the use of cuffed or uncuffed ETTs based on age revealed that more than half of children over 2 years of age were intubated with cuffed ETTs, and that the proportion of cuffed ETTs used dramatically increased in children over 6 years of age (Figure 1). Uncuffed ETTs were used in almost 70\% of neonatal cases, and the proportion of uncuffed ETTs used decreased as age increased (Figure 1).

\subsection{Ill-Fitting ETTs}

Optimal cuffed and uncuffed ETT sizes were selected on the first attempt in 85\% of cases; $15.0 \%$ of cases required multiple attempts to determine the ETT size (second attempt (12.5\%), third attempt (2.3\%), fourth attempt $(0.2 \%)$ ). The proportions of cuffed and uncuffed ETT exchange were $9.6 \%$ and $20.6 \%$, respectively. Analysis of multiple attempts at size selection in 135 cases revealed that an exchange from an uncuffed ETT to a cuffed (37/135) or uncuffed ETT (52/135) was more frequent than an exchange from a cuffed ETT to a cuffed (32/135) or uncuffed ETT (14/135). Laryngeal packing was required in $9.8 \%$ of cases. The

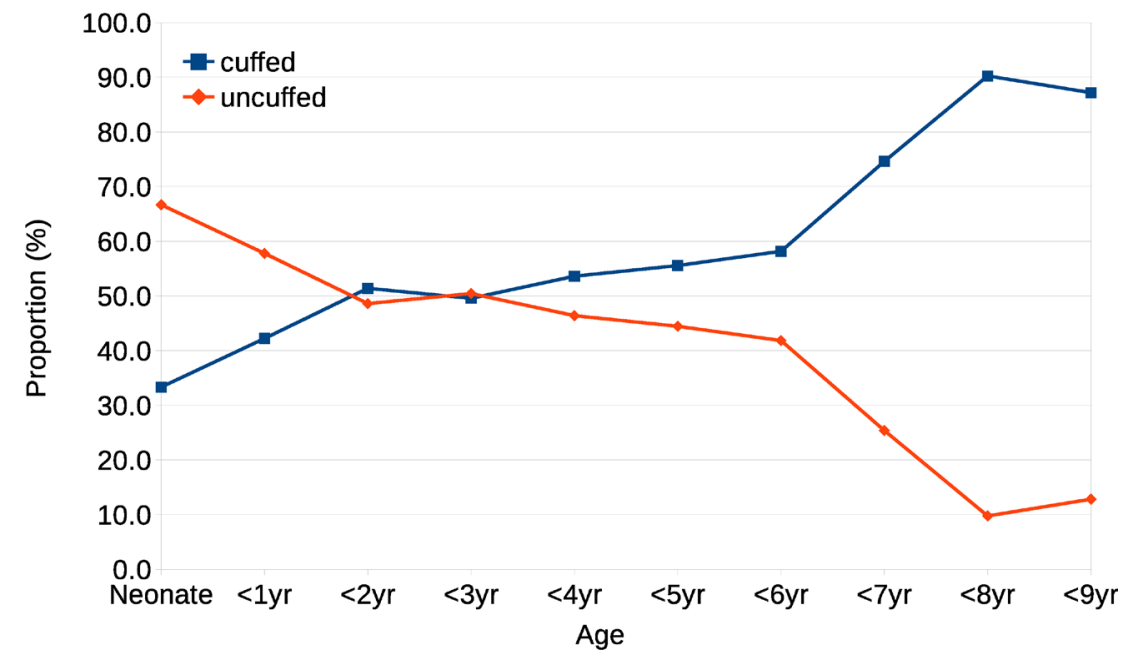

Figure 1. Use of cuffed and uncuffed endotracheal tubes. 
proportion of laryngeal packing in cuffed ETTs (5.6\%) was less than that in uncuffed ETTs (14.9\%).

\subsection{Management of Cuffs}

More than half of cases (503/915) were intubated with cuffed ETTs, and $83.5 \%$ (420/503) of cuffed ETTs were used with the cuff inflated. Analysis of cuffed ETTs with inflated cuffs revealed that ICP was measured in $80.7 \%(339 / 420)$ of cases. However, ICV was measured in $47.1 \%$ (198/420) of cases. The results of the distribution of ICP are detailed in Figure 2. The percentage of cases that measured ICP were $39.5 \%, 18.6 \%, 10.9 \%$, and $9.1 \%$ for pressures of $20,15,10$, and 25 $\mathrm{cmH}_{2} \mathrm{O}$, respectively. The result of the distribution of ICV is detailed in Figure 3. The percentage of cases that measured ICV were $30.8 \%, 23.7 \%$, and $10.1 \%$ for

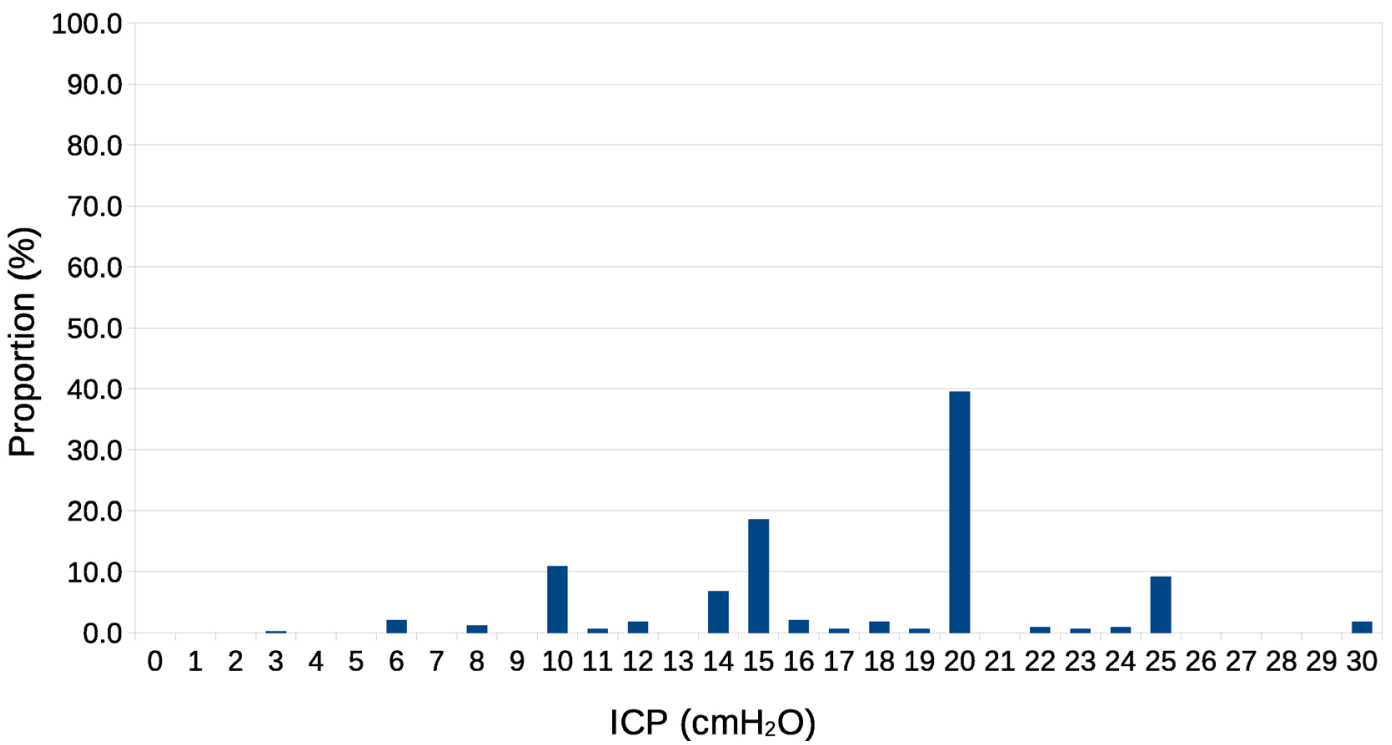

Figure 2. Distributions of intracuff pressure (ICPs).

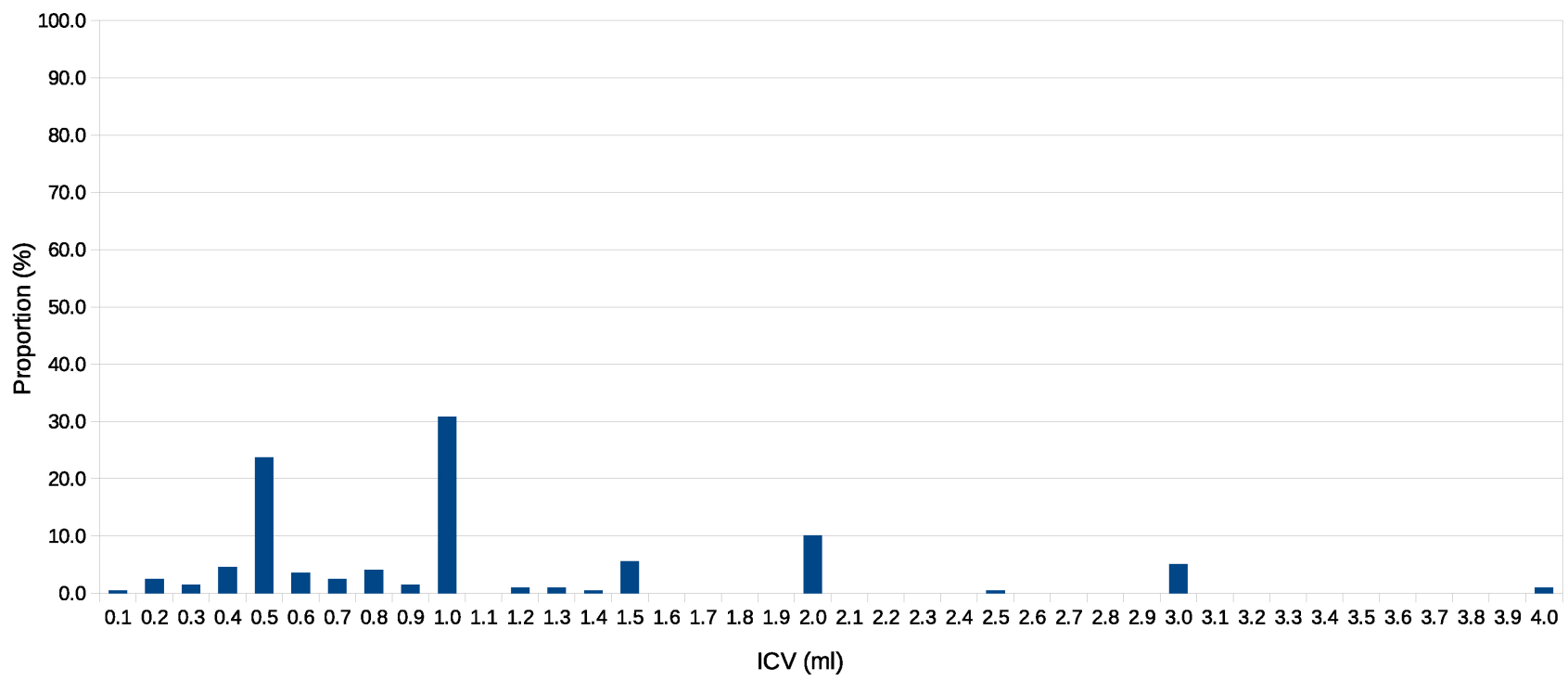

Figure 3. Distributions of intracuff volumes (ICVs). 
volumes of 1.0, 0.5 , and $2.0 \mathrm{~mL}$ respectively. Table 2 shows the results of the time point during surgery when ICP was measured. More than half of cuffed ETTs with the cuff inflated only measured ICP at the time of intubation. The results of scheduled measurement of ICP are detailed in Table 2; more than half of ICP measurements were taken at a frequency of less than every 2 hours during surgery.

\subsection{Extubations and Complications}

Approximately $90 \%$ of all cases were extubated at the end of surgery. Re-intubation was required in only 3 cases. Analysis of extubation at the end of surgery revealed that 7 of $915(0.9 \%)$ of patients suffered post-extubation stridor; 3 of 7 patients required treatment. Stridor was observed in $0.4 \%$ of cuffed and $1.2 \%$ of uncuffed ETTs, respectively. The details of post-extubation stridor are shown in Table 3.

Table 2. Management of endotracheal cuffs. Measurement of ICP (13 cases did not provide responses). Scheduled measurement of ICP (one case did not provide a response).

\begin{tabular}{ccc}
\hline Measurement of ICP & Number of cases & Proportion (\%) \\
\hline No Measurement of ICP & 66 & 16.2 \\
At the time of intubation & 222 & 54.5 \\
Scheduled Measurement & 73 & 17.9 \\
Continuous Measurement & 46 & 11.3 \\
Total & 407 & 100.0 \\
\hline Interval of measurement of ICP & Number of cases & Proportion (\%) \\
\hline$<1 \mathrm{hr}$ & 6 & 8.3 \\
$<2 \mathrm{hr}$ & 33 & 45.8 \\
$<4 \mathrm{hr}$ & 21 & 29.2 \\
$<6 \mathrm{hr}$ & 9 & 12.5 \\
$<8 \mathrm{hr}$ & 1 & 1.4 \\
$<10 \mathrm{hr}$ & 1 & 1.4 \\
$10 \mathrm{hr}$ & 1 & 1.4 \\
Total & 72 & 100.0 \\
\hline
\end{tabular}

Table 3. Detail information on children with post-extubation stridors.

\begin{tabular}{|c|c|c|c|c|c|c|c|c|}
\hline & $\begin{array}{c}\text { Age } \\
\text { (month) }\end{array}$ & $\begin{array}{c}\text { Gender } \\
(\mathrm{M} / \mathrm{F})\end{array}$ & $\begin{array}{c}\text { Duration of } \\
\text { anesthesia (min) }\end{array}$ & Types of ETT & $\mathrm{ICP}\left(\mathrm{cmH}_{2} \mathrm{O}\right)$ & $\begin{array}{c}\text { Numbers of trials } \\
\text { of intubation }\end{array}$ & Treatment & Re-intubation \\
\hline Case 1 & 24 & M & 149 & Cuffed & 15 & 1 & No & No \\
\hline Case 2 & 29 & $\mathrm{~F}$ & 486 & Cuffed & 20 & 2 & No & No \\
\hline Case 3 & 13 & M & 110 & Uncuffed & N/A & 1 & No & No \\
\hline Case 4 & 15 & M & 306 & Uncuffed & N/A & 1 & Yes & No \\
\hline Case 5 & 17 & M & 149 & Uncuffed & N/A & 3 & Yes & No \\
\hline Case 6 & 21 & $\mathrm{~F}$ & 300 & Uncuffed & N/A & 1 & Yes & No \\
\hline Case 7 & 63 & M & 69 & Uncuffed & N/A & 1 & No & No \\
\hline
\end{tabular}

(N/A: Not applicable). 


\subsection{Attitude of Pediatric ETT Management}

Results of the questionnaire concerning the attitude of pediatric ETT management are included in Table 4. Almost half of hospitals did not have institutional criteria for selection of the ETT type. Almost one-third of hospitals did not have

Table 4. Current attitude of pediatric endotracheal tube (ETT) management according to survey results (overlapping answer included).

\begin{tabular}{|c|c|c|c|}
\hline Q1 & Number of Answer & Q4-Uncuffed & Number of Answer \\
\hline No criteria & 23 & Under $20 \mathrm{cmH}_{2} \mathrm{O}$ & 10 \\
\hline Age & 18 & $20-30 \mathrm{cmH}_{2} \mathrm{O}$ & 28 \\
\hline Surgical procedure & 7 & Only check air leakage & 2 \\
\hline Patients position & 5 & & \\
\hline \multirow[t]{2}{*}{ Height } & 2 & Q5 & Number of Answer \\
\hline & & Depth marking & 20 \\
\hline Q2 & Number of Answer & $\begin{array}{l}\text { Bilateral auscultation with } \\
\text { withdrawal of ETT from } \\
\text { bronchial intubation }\end{array}$ & 13 \\
\hline No criteria of weight & 15 & $\begin{array}{l}\text { Calculation based on internal } \\
\text { diameter of ETT }\end{array}$ & 12 \\
\hline Others & 11 & Calculation based on height & 12 \\
\hline $\begin{array}{l}\text { Not use for neonate } \\
\text { under } 3 \mathrm{~kg}\end{array}$ & 10 & No criteria & 7 \\
\hline Older than neonate & 7 & Calculation based on age & 5 \\
\hline Age (month) & 5 & Others & 4 \\
\hline \multirow[t]{2}{*}{ Age (year) } & 3 & & \\
\hline & & Q6 & Number of Answer \\
\hline Q3 & Number of Answer & $\leq 20 \mathrm{cmH}_{2} \mathrm{O}$ & 16 \\
\hline Age & 36 & $\leq 30 \mathrm{cmH}_{2} \mathrm{O}$ & 3 \\
\hline $\begin{array}{l}\text { Recommendation of } \\
\text { manufacturers }\end{array}$ & 4 & Only check ICP & 1 \\
\hline Others & 4 & No criteria & 11 \\
\hline No criteria & 4 & Not measured & 9 \\
\hline Height & 3 & Not inflated cuffs & 1 \\
\hline The fifth finger & 3 & & \\
\hline \multirow[t]{2}{*}{ Weight } & 2 & Q7 & Number of Answer \\
\hline & & Only once & 26 \\
\hline Q4-Cuffed & Number of Answer & Continuous measurement & 6 \\
\hline $15-20 \mathrm{cmH}_{2} \mathrm{O}$ & 19 & Every 60 minutes & 1 \\
\hline $20-30 \mathrm{cmH}_{2} \mathrm{O}$ & 7 & Every 120 minutes & 1 \\
\hline Only check air leakage & 3 & & \\
\hline Deflated & 19 & & \\
\hline
\end{tabular}


weight-based criteria for the selection of cuffed ETTs. More than half of hospitals had criteria based on age for size selection of ETT. In almost half of hospitals, the optimal cuffed ETT size was determined by air leakage at 15 to $20 \mathrm{cmH}_{2} \mathrm{O}$ of airway pressure. However, the optimal uncuffed ETT size was determined by air leakage at 20 to $30 \mathrm{cmH}_{2} \mathrm{O}$ of airway pressure in more than half of hospitals. The top 4 criteria for the determination of ETT depth were depth-marking, withdrawal of the ETT from bronchial intubation, calculation based on the internal diameter of the ETT, and calculation based on height. Almost half of hospitals had institutional criteria for the management of ICP. In most, the ICP value was less than $20 \mathrm{cmH}_{2} \mathrm{O}$. More than half of hospitals measured ICP only once; continuous measurement of ICP was not common.

\section{Discussion}

The response rate of this survey was $66.7 \%$, similar to previous surveys reported from France [3] and the UK [4]. These previous surveys reported the results of pediatric ETT management obtained from specialists in pediatric anesthesia and pediatric intensive care medicine. This survey was conducted not only in children's hospitals, but also in university and general hospitals, and revealed the actual clinical practices of pediatric ETT management more clearly. Moreover, this survey showed that ETTs from more than 5 different brands were used and that a normal ETT was selected for most cases. The most used device for intubation was the laryngoscope; video-assisted laryngoscopes and bronchofiberscope were not used for intubation as often. This result suggested that anesthesiologists primarily selected a laryngoscope for intubation, and that video-assisted laryngoscopes or bronchofiberscopes were selected only for specific cases such as difficult intubations.

More than half of cases in both university and children's hospitals were intubated with cuffed ETTs; the same was not true of cases in general hospitals. This result suggested that more anesthesiologists in general hospitals followed traditional descriptions regarding the use of uncuffed ETTs for children younger than 8 to 10 years of age [1] [2]. Anesthesiologists at all levels of JSA certification selected cuffed ETTs in more than half of cases. This result was different from that of previous surveys in France [3] and the UK [4]. However, these previous surveys were conducted in 2001 and 2008; our survey was conducted in 2016. Furthermore, this study revealed that cuffed ETTs were used in more than half of children over 2 years of age in Japan, which was very different from previous surveys. Cuffed ETTs are usually selected one size smaller than uncuffed ETTs [10] [13]. Some anesthesiologists fear incremental airway resistance and labored breathing due to the smaller internal diameter of cuffed ETTs. However, recent studies have revealed that the airway resistance of an ETT one size smaller did not increase as much as expected under clinical conditions of fresh gas flow [15]. Another recent study revealed that airway pressure measured in the respirator was the pressure of the proximal side of the ETT, and the airway pressure of the 
distal side of the ETT was much less than that of the proximal side [16]. Many clinical investigations revealed the usefulness of cuffed ETTs [8]-[13], and the designs and materials of the cuff were more sophisticated than previous ETTs after the publications of previous surveys [14]. These changes surrounding cuffed ETTs might have a high impact on pediatric ETT management in this survey. Moreover, JSA Qualified Anesthesiologists selected cuffed ETTs much more frequently than did JSA Board Certified Anesthesiologists and Fellow of JSA. "JSA Qualified Anesthesiologist" is the lowest level of certification for anesthesiologists offered by the JSA, and those anesthesiologists were also the youngest of all anesthesiologists. This result suggested that JSA Qualified Anesthesiologists followed more recent descriptions regarding the usefulness of cuffed ETTs [8] [17].

In $85.0 \%$ of cases, the clinically accepted optimal ETT size was selected on the first attempt. The proportions of ETT exchange were $9.6 \%$ and $20.6 \%$ of cuffed and uncuffed ETTs, respectively. Exchanges of ETT size of both cuffed and uncuffed ETTs were required, and these occurred more frequently than in previous studies [8] [10]. The reason why our results of exchange rates were different from those of previous studies might be due to the variety of criteria for ETT size selection in our study. The percentage of exchange of cuffed ETTs was less than that of uncuffed ETTs. Exchange from uncuffed ETTs to cuffed or uncuffed ETTs occurred more frequently than exchange from cuffed ETTs to cuffed or uncuffed ETTs. Moreover, the proportion of laryngeal packing in cuffed ETTs was less than that that of uncuffed ones. In cuffed ETTs, the diameter of the cuff can be optimally adjusted to the diameter of the trachea. Strong air leakage can be blocked by inflating the cuff. The advantages of cuffed ETTs might help anesthesiologists exchange ill-fitting cuffed ETTs less frequently than uncuffed ETTs.

More than $80 \%$ of cuffed ETTs were used with the cuff inflated. Analysis of cases of cuffed ETTs with inflation of the cuff revealed that ICP was measured in $80.7 \%$, and that ICV was measured in $47.1 \%$. This result suggests that the measurement of ICP was more important than the measurement of ICV. The 4 most common values of ICP were $20,15,10$, and $25 \mathrm{cmH}_{2} \mathrm{O}$. The ICP of adult patients should be between 20 and $30 \mathrm{cmH}_{2} \mathrm{O}$ [18] [19] [20] [21] [22]. However, the optimal ICP for pediatric patients remains unclear. These results suggest that anesthesiologists should determine the clinically acceptable ICP, and they might prefer to maintain ICP at these round numbers.

Almost half of ICP measurements were taken only at the time of intubation. ICP was continuously measured and monitored using a manometer during surgeries in only $11.3 \%$ of cases. Scheduled ICP measurement was performed in $17.9 \%$ of cuffed ETTs with inflated of cuffs. The interval of ICP measurement was within 2 hours in more than half of scheduled measurements, but was dependent on the duration of the surgery. ICP was continuously measured and monitored during intubation. However, the optimal ICP for pediatric patients 
remains unclear. Moreover, the cuff diameters even at the same ICP are quite different [23]. Further studies to determine the optimal ICP for pediatric patients are necessary.

Almost $90 \%$ of patients were extubated at the end of surgery. Only $7(0.9 \%)$ patients had post-extubation stridor, and $3(0.3 \%)$ required additional treatment for post-extubation stridor. The proportions of post-extubation stridor were $0.4 \%$ and $1.2 \%$ of patients with cuffed and uncuffed ETTs, respectively. The proportion of post-extubation stridor and additional treatment for post-extubation stridor in this study were much lower than those in previous studies [8]. Although there were many criteria for ETT size selection in our study, anesthesiologists might pay more attention to the selection of the optimal ETT size, and also set the ICPs at the clinically optimal value.

\section{Conclusion}

Our study revealed widespread use of cuffed ETTs in children over 2 years of age, and that ICPs of cuffed ETTs were measured using a manometer. Moreover, post-extubation stridor in both cuffed and uncuffed ETTs was rarely observed in clinical practice. However, the optimal ICP for children remains unclear, and further study is necessary.

\section{Acknowledgements}

We would like to thank the following institutions for their participation: Anjo Kosei Hospital, Okayama University, Kansai Medical University, Gifu Prefectural General Medical Center, Miyagi Children's Hospital, Hiroshima Prefectural Hospital, Hiroshima University, Kagawa University, Mie University, Yamanashi Prefectural Central Hospital, Shikoku Medical Center for Children and Adults, Jichi Medical University, Kagoshima University, Showa University, National Center for Child Health and Development, St. Marianna University School of Medicine, Shizuoka Children's Hospital, Ishikawa Prefectural Central Hospital, Kawasaki Medical School, Osaka Medical College, Japanese Red Cross Osaka Hospital, Osaka University, Osaka Women's and Children's Hospital, University of Tsukuba, Nagano Children's Hospital, Toho University, Tohoku University, Tokyo Medical and Dental University, Tokushima University, Nihon University, Hyogo Prefectural Kobe Children's Hospital, Hokkaido Medical Center for Child Health and Rehabilitation, Kitakyushu Municipal Hospital, Kitano Hospital, Nagoya City University, University of the Ryukyus, Kanagawa Children's Medical Center, University of Fukui, Fukuoka Children's Hospital, Fukushima Medical University, Tokyo Metropolitan Children's Medical Center, Kyoto Prefectural University of Medicine.

\section{Funding}

This study was partially supported by Halyard Healthcare, Inc. 


\section{Availability of Data and Materials}

The datasets of this study are available from the corresponding author after approval of the JSPA.

\section{Authors' Contributions}

MS designed this study, and conducted the data analysis, and drafted the manuscript. YS, TK, YK, KM and NS designed this study and drafted the manuscript. All authors interpreted the data and revised manuscript, and approval the final version of the manuscript.

\section{Ethical Approval and Informed Consent}

The protocol for this study was approved by the Japanese Society of Pediatric Anesthesiology (JSPA). The institutional ethical review board of each participating hospital approved this study and waived the requirement of informed consent.

\section{Consent for Publication}

Not applicable.

\section{Conflicts of Interest}

The authors have no conflicts of interest to declare.

\section{References}

[1] Veyckemans, F. (1999) New Developments in the Management of the Paediatric Airway: Cuffed or Uncuffed Tracheal Tubes, Laryngeal Mask Airway, Cuffed Oropharyngeal Airway, Tracheostomy and One-Lung Ventilation Devices. Current Opinion in Anesthesiology, 12, 315-320. https://doi.org/10.1097/00001503-199906000-00010

[2] Motoyama, E.K. (1990) Endotracheal Intubation. In: Motoyama, E.K. and Davis, P.J., Eds., Smith's Anesthesia for Infants and Children, CV Mosby, St Louis, 269-275.

[3] Orliaguet, G.A., Renaud, E., Lejay, M., Meyer, P.G., Schmautz, E., Telion, C., et al. (2001) Postal Survey of Cuffed or Uncuffed Tracheal Tubes Used for Paediatric Tracheal Intubation. Pediatric Anesthesia, 11, 277-281. https://doi.org/10.1046/j.1460-9592.2001.00689.x

[4] Flynn, P., Black, A. and Mitchell, V. (2008) The Use of Cuffed Tracheal Tubes for Paediatric Tracheal Intubation, a Survey of Specialist Practice in the United Kingdom. European Journal of Anaesthesiology, 25, 685-688. https://doi.org/10.1017/S0265021508003839

[5] James, I. (2001) Cuffed Tubes in Children. Pediatric Anesthesia, 11, 259-263. https://doi.org/10.1046/j.1460-9592.2001.00675.x

[6] Holzki, J. (1997) Laryngeal Damage from Tracheal Intubation. Pediatric Anesthesia, 7, 435-437. https://doi.org/10.1046/j.1460-9592.1997.d01-127.x

[7] Dillier, C.M., Trachsel, D., Baulig, W., et al. (2004) Laryngeal Damage Due to an Unexpectedly Large and Inappropriately Designed Cuffed Pediatric Tracheal Tube 
in a 13-Month-Old Child. Canadian Journal of Anaesthesia, 51, 72-75. https://doi.org/10.1007/BF03018551

[8] Weiss, M., Dullenkopf, A., Fischer, J.E., et al. (2009) Prospective Randomized Controlled Multi-Centre Trial of Cuffed or Uncuffed Endotracheal Tubes in Small Children. British Journal of Anaesthesia, 103, 867-873. https://doi.org/10.1093/bja/aep290

[9] Fine, G.F., Fertal, K. and Motoyama, E.K. (2000) The Effectiveness of Controlled Ventilation Using Cuffed versus Uncuffed ETT in Infants. Anesthesiology, 93, A1251.

[10] Khine, H.H., Corddry, D.H., Kettrick, R.G., et al. (1997) Comparison of Cuffed and Uncuffed Endotracheal Tubes in Young Children during General Anesthesia. Anesthesiology, 86, 627-631. https://doi.org/10.1097/00000542-199703000-00015

[11] Dullenkopf, A., Gerber, A.C. and Weiss, M. (2005) Fit and Seal Characteristics of a New Paediatric Tracheal Tube with High Volume-Low Pressure Polyurethane Cuff. Acta Anaesthesiologica Scandinavica, 49, 232-237. https://doi.org/10.1111/j.1399-6576.2005.00599.x

[12] Newth, C.J., Rachman, B., Patel, N., et al. (2004) The Use of Cuffed versus Uncuffed Endotracheal Tubes in Pediatric Intensive Care. Journal of Pediatrics, 144, 333-337. https://doi.org/10.1016/j.jpeds.2003.12.018

[13] Duracher, C., Schmautz, E., Martinon, C., et al. (2008) Evaluation of Cuffed Tracheal Tube Size Predicted Using the Khine Formula in Children. Pediatric Anesthesia, 18, 113-118.

[14] Weiss, M., Dullenkopf, A. and Gerber, A.C. (2004) Microcuff Pediatric Tracheal Tube. A New Tracheal Tube with a High Volume-Low Pressure Cuff for Children. Anaesthesist, 53, 73-79. https://doi.org/10.1007/s00101-003-0604-X

[15] Manczur, T., Greenough, A., Nicholson, G.P., et al. (2000) Resistance of Pediatric and Neonatal Endotracheal Tubes: Influence of Flow Rate, Size, and Shape. Critical Care Medicine, 28, 1595-1598. https://doi.org/10.1097/00003246-200005000-00056

[16] Spaeth, J., Steinmann, D., Kaltofen, H., et al. (2015) The Pressure Drop across the Endotracheal Tube in Mechanically Ventilated Pediatric Patients. Pediatric Anesthesia, 25, 413-420. https://doi.org/10.1111/pan.12595

[17] Shi, F., Xiao, Y., Xiong, W., et al. (2016) Cuffed versus Uncuffed Endotracheal Tubes in Children: A Meta-Analysis. Journal of Anesthesia, 30, 3-11. https://doi.org/10.1007/s00540-015-2062-4

[18] American Thoracic Society, Infectious Diseases Society of America (2005) Guidelines for the Management of Adults with Hospital-Acquired, Ventilator-Associated, and Healthcare-Associated Pneumonia. American Journal of Respiratory and Critical Care Medicine, 171, 388-416. https://doi.org/10.1164/rccm.200405-644ST

[19] Sengupta, P., Sessler, D.I., Maglinger, P., et al. (2004) Endotracheal Tube Cuff Pressure in Three Hospitals, and the Volume Required to Produce an Appropriate Cuff Pressure. BMC Anesthesiology, 4, 8. https://doi.org/10.1186/1471-2253-4-8

[20] Pneumatikos, I.A., Dragoumanis, C.K. and Bouros, D.E. (2009) Ventilator-Associated Pneumonia or Endotracheal Tube-Associated Pneumonia? An Approach to the Pathogenesis and Preventive Strategies Emphasizing the Importance of Endotracheal Tube. Anesthesiology, 110, 673-680. https://doi.org/10.1097/ALN.0b013e31819868e0

[21] Rello, J., Soñora, R., Jubert, P., et al. (1996) Pneumonia in Intubated Patients: Role of Respiratory Airway Care. American Journal of Respiratory and Critical Care Medicine, 154, 111-115. https://doi.org/10.1164/ajrccm.154.1.8680665 
[22] Seegobin, R.D. and van Hasselt, G.L. (1984) Endotracheal Cuff Pressure and Tracheal Mucosal Blood Flow: Endoscopic Study of Effects of Four Large Volume Cuffs. British Medical Journal (Clinical Research Edition), 288, 965-968. https://doi.org/10.1136/bmj.288.6422.965

[23] Weiss, M., Dullenkopf, A., Gysin, C., et al. (2004) Shortcomings of Cuffed Paediatric Tracheal Tubes. British Journal of Anaesthesia, 92, 78-88.

https://doi.org/10.1093/bja/aeh023

\section{Abbreviations}

ETT: Endotracheal tube

ICP: Intracuff pressure

ICV: Intracuff volume

JSA: Japanese Society of Anesthesiologists

JSPA: Japanese Society of Pediatric Anesthesiology 